\title{
INTERPRETATION OF VLF MEASUREMENTS RELATED TO HYDROGEOLOGICAL SURVEYS
}

\author{
Vargemezis G. ${ }^{1}$ \\ ${ }^{I}$ Department of Geophysics, Aristotle's University of Thessaloniki, GREECE, varge@geo.auth.gr
}

\begin{abstract}
The aim of the application of VLF surveys in hydrogeology is the contribution to the decision making as concern the construction of a well. Geophysical survey by the application of VLF method must respond to the questions (a) if the construction of a well should be proposed or not, and if the answer is yes then (b) where exactly must be located. These answers are very crucial ones, since VLF methods is applied mainly in areas where bedrock is close to the surface and no chance has a well if it will not drill an aquiferous fault.

Problems arise by the fact that the target to be detected is a conductive body which is interpreted as a fault filled with water. The major question that is posed to the surveyor is if the conductivity of the fault is caused by fresh water or by clay materials or saline water.

Forward models of different resistivity contrast between host rock and conductive body have been computed and examined.

Results show that interpretation of the imaginary part is very important to the evaluation of the data. Since the conductor -in the meaning of water presence onlymust be a medium one, a high value of the real part should be expected in parallel with a close to 0 value of the imaginary component which also must show one peak to the Fraser filtered data.
\end{abstract}

Key words: VLF, hydrogeology.

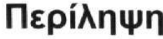

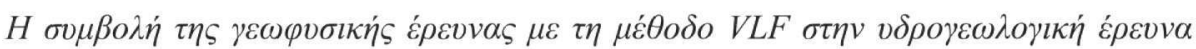

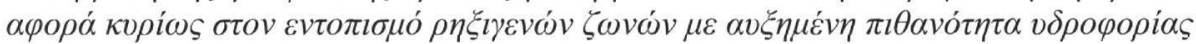

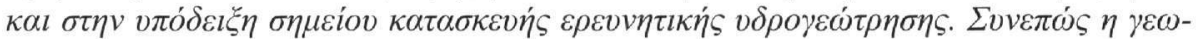

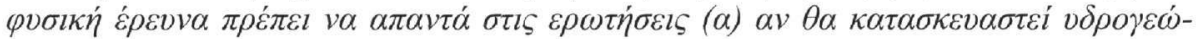

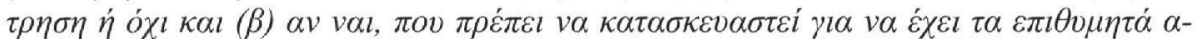

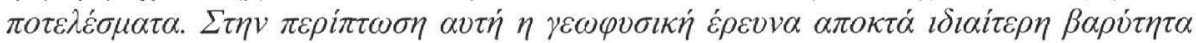

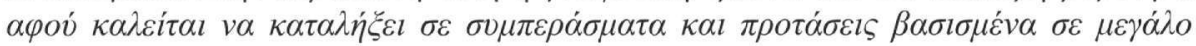

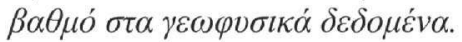

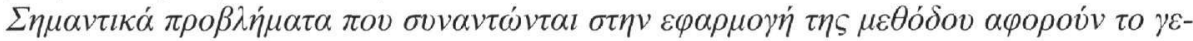

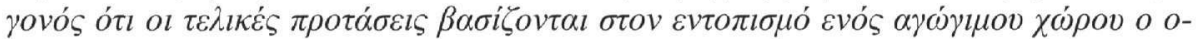

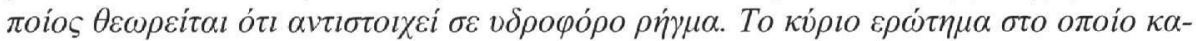

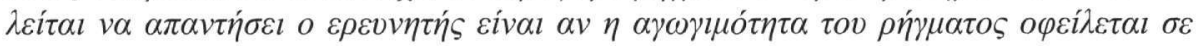

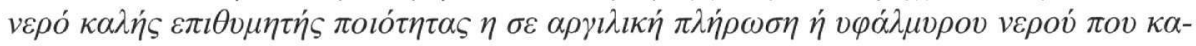

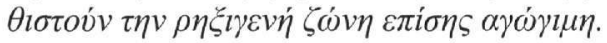




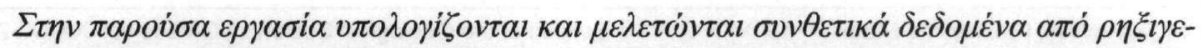

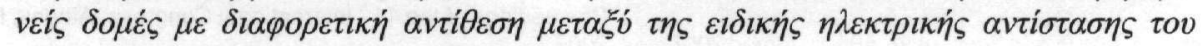

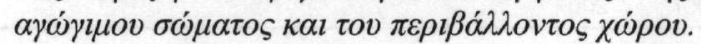

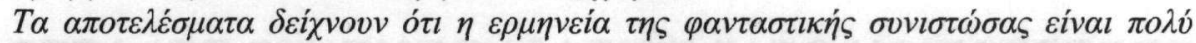

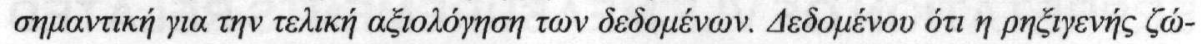

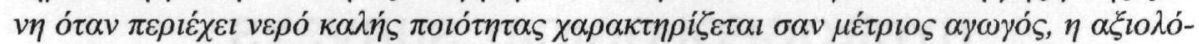

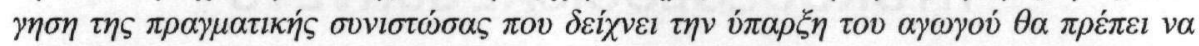

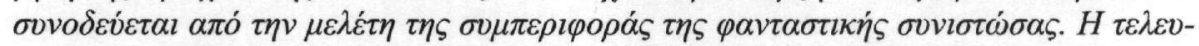

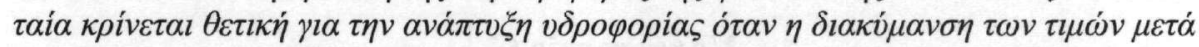

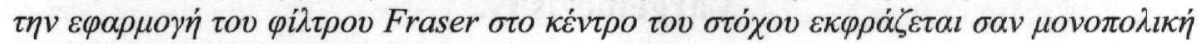

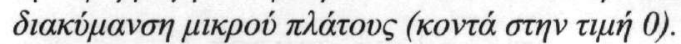

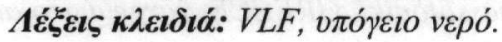

\section{Introduction}

VLF (Very Low Frequency) is a widely used method to the detection of aquiferous faulting systems. The advantages of the specific electromagnetic method are that (a) it is very quick in fieldwork, (b) light equipment is used and (c) the data collected are quit easy to be interpreted in a qualitative manner. It is a favourable tool for many professional geologists-geophysicists as well of many researchers who apply VLF methods in addition with other geophysical methods in order to study hydrogeological problems as well as geotechnical ones (Benson 1997, Sampaio and Dias 2001, Hautot et al. 2002, Sharma and Baranwal 2005, Drahor and Berge 2006, Monteiro Santos et al. 2006 a, b, Zlotnicki et al. 2006).

The method is effective in areas where bedrock having high resistivity values is close to the surface with no or of low thickness overburden, conditions which permit the maximum of the penetration depth. Real and Imaginary parts of the horizontal magnetic component which is perpendicular to the EM field propagation are recorded and interpreted in order to detect vertical or inclined conductive bodies (in comparison to the rock host resistivity). These bodies are thought to reflect the existence of faults which are conductive cause of the presence of water or clay mainly that are filling the porous in the cracks.

In result, VLF method is very effective to produce accurate information about the location, the inclination of probable aquiferous faults and finally to make decision about the exact point where a well must be constructed.

Problems arise by the fact that conductive fault could be filled or by water or by clay materials. In the second case the conductive body will be drilled but no water at all will be found. That difficulty poses ambiguities about the effectiveness of the methods to the major target which is the decision making about constructing a well or not.

In the present paper the response of VLF data to various models concerning the resistivity of the host rock and resistivity and depth of the conductive body is studied.

Different models are constructed by the mean of the water quality and the presence of clay, and the response of the VLF measurements is estimated, in order to contribute to the qualitative interpretation by the mean of the decision making.

Finally two examples of field data are presented, a successful case and a failed one.

\section{VLF method}

The Very Low Frequency (VLF) electromagnetic method takes advantage of electromagnetic radiation generated in the low frequency band of $15-25 \mathrm{kHz}$ by military radio transmitters used in long-range communications and navigational systems (e.g. Parasnis 1995). Many stations around the globe transmit within this frequency range. At distances greater than $100 \mathrm{~km}$ from the source 
the electromagnetic field is planar with the magnetic component horizontal. The electric component is in a vertical plane perpendicular to the magnetic component in the direction of propagation.

In the absence of subsurface electric conductors the transmitted signal is horizontal and linearly polarized. When a conductor (like a fracture zone) is crossed by the electromagnetic field an induced current flows through it and produces a secondary magnetic field out-of-phase with the primary magnetic field oriented in any direction (McNeill and Labson 1990). The vector sum of the two magnetic fields traces out an ellipse with time, the tilt of which is measured in the VLF tilt angle mode (Fig. 1). This tilt is approximately equal to the in-phase part of the vertical component of the magnetic field ellipse (Parasnis 1995).

Therefore the VLF electromagnetic method is useful for detecting long, straight electrical conductors, such as faults or fractured systems, filled with water or clay.

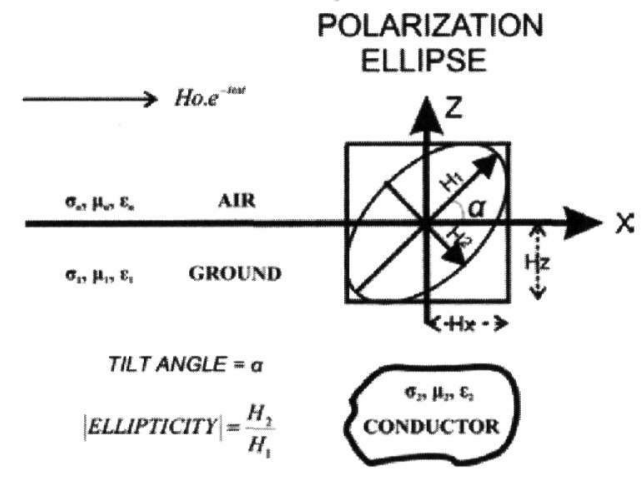

Figure 1 - Scheme showing the ellipticity produced by the secondary electromagnetic field (reproduced by Saydam 1986). Transmitter is located along the $Y$ direction

Thus, measuring along a profile which crosses a deep inclined fault, real (in phase) and imaginary (out of phase) components draw bipolar anomalies which reflect the existence of the conductor (Fig. 2).

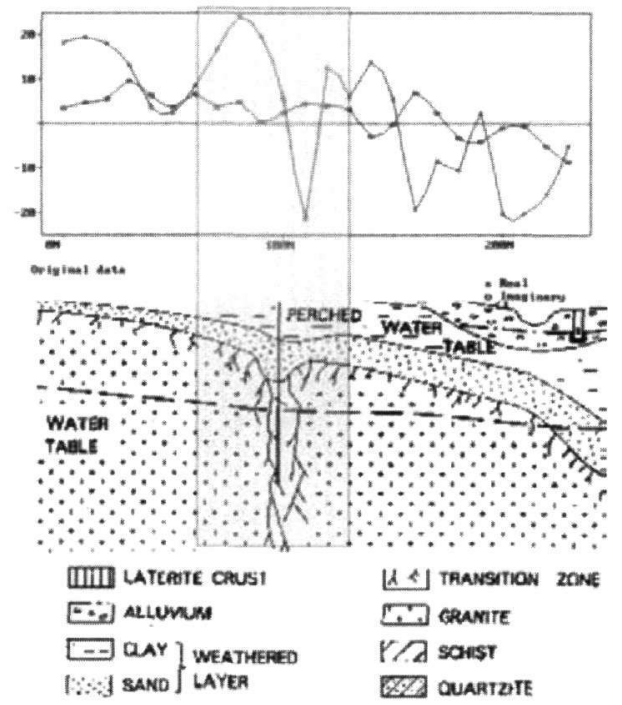

Figure 2 - Typical example of a VLF profile measured over a conductive zone

In the figure above one can see the bipolar anomaly of the Real component over the faulting zone which is thought to be an aquiferous system. 
In the first place, qualitative interpretation is achieved by observing crosses of the real and imaginary component which point the projection of the conductor to the surface. Conductor depth is estimated by the division by two of the horizontal distance between the maximum and the minimum value of the real part. That is, in the case presented above approximately 15 meters.

Interpretation procedures have been proposed in order to make the evaluation of the data more accurate and effective. The major ones are the filters that may be applied to the data sets proposed by Fraser (1969) and Karous and Hjelt (1983).

Fraser filter is described by the equation below:

$$
f_{2,3}=\left(M_{3}+M_{4}\right)-\left(M_{1}+M_{2}\right)
$$

The value is plotted between M2 and M3 points. The effectiveness of the filter proposed by Fraser is that it converts bipolar anomalies to monopolar curves having the positive peak over the conductor. Thus, filtered data provide a data presentation which simplifies interpretation.

Karous and Hjelt developed a statistical linear filter, based on Fraser. This filter provides an apparent depth profile from the current density (Ho) which is derived from the magnitude of the vertical component of the magnetic field a a specific location (Hutchinson and Barta 2002). The depth profile can be calculated from

$$
I_{a}(0)=\frac{2 \pi\left(-0.102 H_{-3}+0.059 H_{-2}-0.561 H_{-1}+0.561 H_{1}-0.059 H_{2}+0.102 H_{3}\right)}{z}
$$

Where the equivalent current density $\mathrm{I}_{\mathrm{a}}$ at a specified horizontal position and depth $\mathrm{z}$ is based on a symmetrical filter of the measured current (from the measured magnetic component of the anomalous field).

Karous-Hjelt filter permits the draw of cross sections which show the response of the conductor in depth.
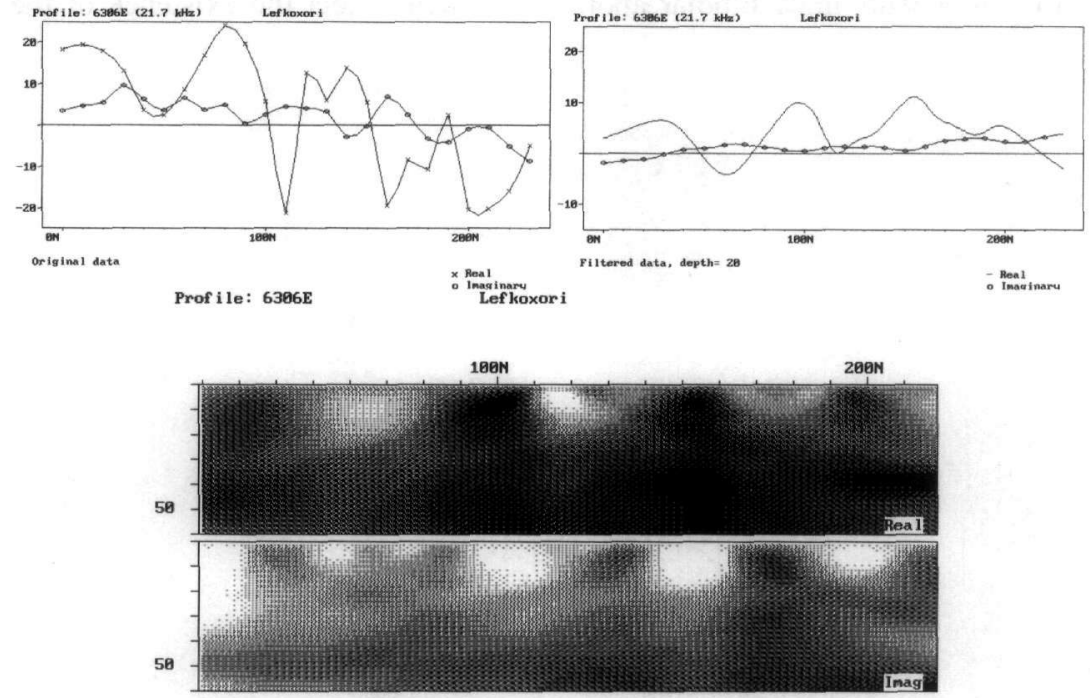

Figure 3 - At upper figure raw data are presented while in the middle one Fraser filter is applied and at the bottom cross section where Karous-Hjelt filter is applied (data processed with SECTOR program)

In the figure above one can see that crosses between real and imaginary component have been transformed to positive peaks over the conductor. 
Nissen (1986) offered for free his software where someone can calculate the VLF response of conductor taking account their geometry and resistivity in a resistive host rock medium. That is very efficient since the resistivity of the host rock is taking into account and allows to someone to approach a quantitative geoelectrical model of the cross section along the measured profile.

Other efforts have been done in order to get more accurate information about the conductivity of the detected body which can be used for the determination of its nature (Saydam 1981, Kaikkonen and Sharma 1998, Gharibi and Pedersen 1999).

In the practical way of interpreting VLF data Saydam (1981) suggests that the amplitude and the shape of tilt angle and ellipticity anomalies obtained over sheet-like conductors at VLF are mainly affected by (a) the conductivity-thickness product of the conductor, (b) the resistivity of surrounding medium, depth to top of conductor, and overlying conductive overburden. Frequency within the range of $15-30 \mathrm{kHz}$ does not have a significant effect on the VLF response of a conductor.

Also, the topography effect on the magnetic field has to be considered along VLF profiles. When the VLF wave reaches an inclined surface the magnetic field component perpendicular to the surface induces currents into the ground. These currents create a secondary magnetic field out of phase with the incident one. The sum of the magnetic fields becomes elliptically polarized and a tilt anomaly is produced even the Earth is assumed to be homogeneous (Parasnis 1995).

If the depth penetration in the ground of the VLF wave is small (some tens of metres), the effect of the topography generates an inclined anomaly, positive going up the slope and negative going down with a crossover at the crest or the bottom of the anomaly. The effect of topography must be assessed before a true VLF tilt-angle anomaly can be ascribed to a deep geological conductor. This topographic effect can be removed from data using the method proposed by Nissen.

\section{Resistivity of sheet-like conductors.}

In order to proceed to the calculation of forward models, probable geoelectrical 2D models must be assumed in order to get near to realistic geological models that could be surveyed.

The characteristics of these models must contain information about the resistivity of the host rock, the depth and the width of the conductor and finally its resistivity.

Speaking about application of VLF method in hydrogeological purposes we must consider of the expected resistivity of a faulting zone in case that the filling material of the secondary porosity is water or clay. In case of the water we must also assume

Table 1 - Numeric values for various types of water

\begin{tabular}{|c|c|c|}
\hline Type of water & $\mathrm{Cf}(\mu \mathrm{S} / \mathrm{cm})$ & $\mathrm{Rf}(\mathrm{Ohm} . \mathrm{m})$ \\
\hline Very fresh & 50 & 200.0 \\
\hline Potable & 400 & 25.0 \\
\hline Fresh & 500 & 20.0 \\
\hline Salted & 1000 & 10.0 \\
\hline Accepted for irrigation & 2000 & 5.0 \\
\hline Forbitten for irrigation & 3000 & 3.3 \\
\hline Very salted (Sea water) & 30000 & 0.3 \\
\hline
\end{tabular}
different water conductivities in order to approach the desired conductivity of fresh water or at least the accepted one for several uses. That must be taken into account in order to avoid the case that saline water could fill the fault.

Considering that water conductivity is an accepted criterion for the characterization of the water quality as concern its conciseness in salts, the table 1 gives several characteristic values. In the right column of the table the resistivity of the water is presented. 
Since we assumed the resistivity of the water, we can estimate the expected resistivity value for the fault that host the water which is the conductor detected. That can be achieved by the use of Archie's law (Archie 1942) since theoretically no clay is expected to be in the fracture system.

$$
\rho_{\text {ROCK }}=\rho_{\text {FLUID }} \cdot A \cdot \varphi^{-m}
$$

Where $p_{R O C K}$ is the effective resistivity, $\rho_{\text {FLUID }}$ equals the electrical properties of the fluid in the pores, $\varphi$ is the porosity and $A, m$ are constants that depend on the geometry of the pores.

For many rocks, $\mathrm{A}=$ about 1 and $\mathrm{m}=$ about 2 . The table below shows more discriminating values for $\mathrm{A}$ and $\mathrm{m}$ for different types of rocks.

Table 2 - Archie parameters for different types of rocks (Keller 1996)

\begin{tabular}{|l|c|c|c|}
\hline Rock Type & $\varphi$ & $\mathrm{A}$ & $\mathrm{m}$ \\
\hline 1. Weakly cemented & $0.25-0.45$ & 0.88 & 1.37 \\
\hline 2. Moderately well cemented & $0.22-0.35$ & 0.62 & 1.72 \\
\hline 3. Well cemented & $0.05-0.25$ & 0.62 & 1.95 \\
\hline 4. Dense, igneous, metamorphic & $<0.05$ & 1.4 & 1.6 \\
\hline 5. High porosity volcanic & $0.2-0.8$ & 3.5 & 1.4 \\
\hline
\end{tabular}

Calculation of the expected conductor resistivity in a range of water conductivity and porosity is presented to the following table.

Table 3 - Classification of rocks resistivity with rock types and porosity ( $\rho$ corresponds to the resistivity of the fault zone and $\sigma$ to the conductivity of the water). Porosity, water conductivity values and rock types that we are interested in are in bold

\begin{tabular}{|c|c|c|c|c|c|c|c|}
\hline $\begin{array}{c}\rho \\
(\mathrm{Ohm}-\mathrm{m})\end{array}$ & $\begin{array}{c}\sigma \\
(\mu \mathrm{S} / \mathrm{cm})\end{array}$ & $\varphi$ & $\begin{array}{l}\text { Rock } \\
\text { Type }\end{array}$ & $\begin{array}{c}\rho \\
(\mathrm{Ohm}-\mathrm{m})\end{array}$ & $\begin{array}{c}\sigma \\
(\mu \mathrm{S} / \mathrm{cm})\end{array}$ & $\varphi$ & $\begin{array}{l}\text { Rock } \\
\text { Type }\end{array}$ \\
\hline \multirow{6}{*}{$0-10$} & 30000 & 0.25 & 1 & \multirow{4}{*}{$101-125$} & 500 & 0.25 & 1 \\
\hline & 30000 & 0.45 & 1 & & 400 & 0.45 & 1 \\
\hline & 30000 & 0.22 & 2 & & 3000 & 0.2 & 5 \\
\hline & 30000 & 0.35 & 2 & & 400 & 0.8 & 5 \\
\hline & 30000 & 0.25 & 3 & $126-150$ & 400 & 0.25 & 1 \\
\hline & 30000 & 0.8 & 5 & \multirow{3}{*}{$151-200$} & 500 & 0.22 & 2 \\
\hline \multirow{6}{*}{$11-20$} & 3000 & 0.25 & 1 & & 500 & 0.25 & 3 \\
\hline & 3000 & 0.45 & 1 & & 2000 & 0.2 & 5 \\
\hline & 3000 & 0.35 & 2 & \multirow{2}{*}{$201-300$} & 400 & 0.22 & 2 \\
\hline & 2000 & 0.35 & 2 & & 400 & 0.25 & 3 \\
\hline & 30000 & 0.2 & 5 & $301-500$ & 1000 & 0.2 & 5 \\
\hline & 3000 & 0.8 & 5 & \multirow{3}{*}{$501-750$} & 3000 & 0.05 & 3 \\
\hline \multirow{4}{*}{$21-30$} & 2000 & 0.25 & 1 & & 3000 & 0.05 & 4 \\
\hline & 2000 & 0.45 & 1 & & 500 & 0.2 & 5 \\
\hline & 3000 & 0.22 & 2 & \multirow[t]{2}{*}{$751-1000$} & 50 & 0.45 & 1 \\
\hline & 2000 & 0.8 & 5 & & 50 & 0.35 & 2 \\
\hline
\end{tabular}




\begin{tabular}{|c|c|c|c|c|c|c|c|}
\hline \multirow{2}{*}{$31-40$} & 1000 & 0.35 & 2 & & 2000 & 0.05 & 4 \\
\hline & 3000 & 0.25 & 3 & & 400 & 0.2 & 5 \\
\hline \multirow{4}{*}{$41-50$} & 1000 & 0.45 & 1 & & 50 & 0.8 & 5 \\
\hline & 2000 & 0.22 & 2 & \multirow{2}{*}{$1001-1500$} & 50 & 0.25 & 1 \\
\hline & 2000 & 0.25 & 3 & & 2000 & 0.05 & 3 \\
\hline & 1000 & 0.8 & 5 & \multirow{3}{*}{$1501-2000$} & 50 & 0.22 & 2 \\
\hline \multirow{2}{*}{$51-60$} & 1000 & 0.25 & 1 & & 50 & 0.25 & 3 \\
\hline & 30000 & 0.05 & 4 & & 1000 & 0.05 & 4 \\
\hline \multirow{2}{*}{$71-80$} & 500 & 0.35 & 2 & $2001-3000$ & 1000 & 0.05 & 3 \\
\hline & 30000 & 0.05 & 3 & $3001-4000$ & 500 & 0.05 & 4 \\
\hline $81-90$ & 1000 & 0.22 & 2 & \multirow{2}{*}{$4001-5000$} & 500 & 0.05 & 3 \\
\hline \multirow{5}{*}{$91-100$} & 500 & 0.45 & 1 & & 400 & 0.05 & 4 \\
\hline & 400 & 0.35 & 2 & $5001-6000$ & 400 & 0.05 & 3 \\
\hline & 1000 & 0.25 & 3 & $6001-7000$ & 50 & 0.2 & 5 \\
\hline & 500 & 0.8 & 5 & $>10000$ & 50 & 0.05 & 3 \\
\hline & & & & & 50 & 0.05 & 4 \\
\hline
\end{tabular}

As we can see to the table above the range of the resistivity values that correspond with 'good' aquifers by the meaning of the quality of the water is very large. It varies from 30 to 6000 depending on the rock type and the porosity.

If we apply the porosity of at least 0.2 like a second criterion considering the amount of the water that we are interested in then the range becomes:

Table 3 - Classification of rocks resistivity with rock types and porosity after criteria application

\begin{tabular}{|l|c|c|c|}
\hline \multicolumn{1}{|c|}{ Rock Type } & $\varphi$ & $\rho(\mathrm{Ohm}-\mathrm{m})$ & $\sigma(\mu \mathrm{S} / \mathrm{cm})$ \\
\hline 1. Weakly cemented & $0.25-0.45$ & $51-125$ & $400-1000$ \\
\hline 2. Moderately well cemented & $0.22-0.35$ & $30-300$ & $400-1000$ \\
\hline 3. Well cemented & 0.25 & $91-300$ & $400-1000$ \\
\hline 5. High porosity volcanic & $0.2-0.8$ & $41-1000$ & $400-1000$ \\
\hline
\end{tabular}

The table above shows the expected resistivity for different geological formations where VLF investigation is taking place.

\section{VLF forward modelling}

Following classification described above forward modelling has been done using Nissen's software with following parameters.

Resistivity of host rock: $5000 \mathrm{Ohm}-\mathrm{m}$

Depth: 20 to 40 meters
Resistivity of conductor: 2 to 1000 Ohm-m

Width: 5 to 10 meters.

The synthetic curves (raw and filtered) are presented in Fig. 4. 

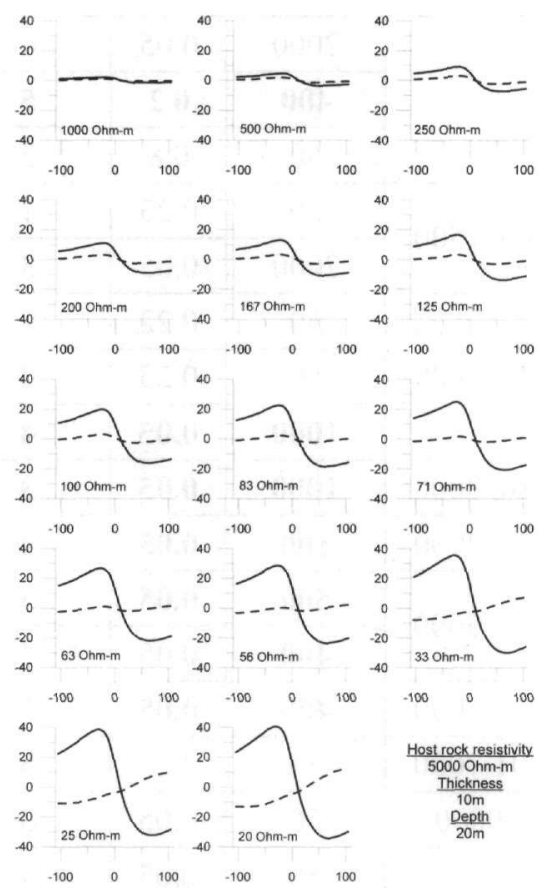

71 Ohm-m
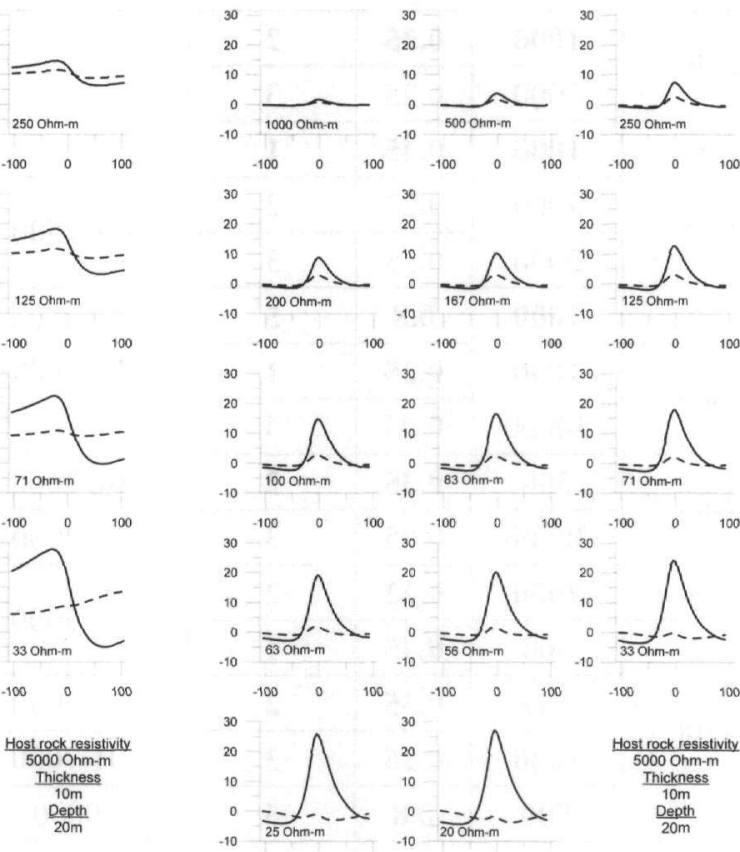

Figure 4 - Raw (on the left) and filtered (Fraser) data (on the right). Real part corresponds to dense line while Imaginary part corresponds to the dashed one. Vertical axis is in $\%$ of the tilt angle (Real component) and ellipticity (Imaginary component)

Increasing conductor's resistivity the amplitude of the anomaly becomes weaker (Fig. 4). In real data resistivity higher than $250 \mathrm{Ohm}-\mathrm{m}$ can not be recognised easily. That is not considered to be a serious problem because in a few cases only high resistivity values are expected. Main problem refers to low resistivity values where saline water or clay (of approximately $10 \mathrm{Ohm}$-m resistivity) are expected to be a problem. That we see in curves corresponding to resistivity values less than 50 $\mathrm{Ohm}-\mathrm{m}$ is that imaginary part starts to behave differently. In raw data they start to draw away from the value of 0 that is the desirable having a variation with large amplitude. In filtered data even they approach the value of 0 , anomalies of high frequency appear symmetrically to the position of the target since in higher resistivity values they show only a slight peak in the specific point. Value of filtered real part in the desired range varies from 10 to $20 \%$.

When targets have resistivity more than $83 \mathrm{Ohm}-\mathrm{m}$ they are very difficult to be recognised in field data since the amplitude is less than $5 \%$ (Fig. 5). Another notice that can be made is that Imaginary part draws away from 0 value earlier than the first case, in the resistivity of $56 \mathrm{Ohm}-\mathrm{m}$ in raw data and becomes negative in low resistivities in filtered data.

In the case the value of the filtered real part in the desired resistivity range varies from 5 to $8 \%$.

Considering that the host rock resistivity is $5000 \mathrm{Ohm}-\mathrm{m}$ that range corresponds to resistivity contrast as concern the fault zone resistivity at the range of $1 / 125$ to $1 / 30$.

The example in Fig. 6 describes a thinner target than the expected of $10 \mathrm{~m}$ in most cases of faults.

We see that in raw data anomalies it is difficult to be discriminated in resistivity values higher than $100 \mathrm{Ohm}-\mathrm{m}$. It is very interesting that imaginary component changes behaviour dramatically. It is always close to 0 and in addition in filtered data it is always producing a positive peak. That makes difficult to the investigator to diagnose a very conductive body and make the right decision as concern the construction of a well or not.

In the case value of the filtered real part in the desired resistivity range varies from 2 to $6 \%$. 


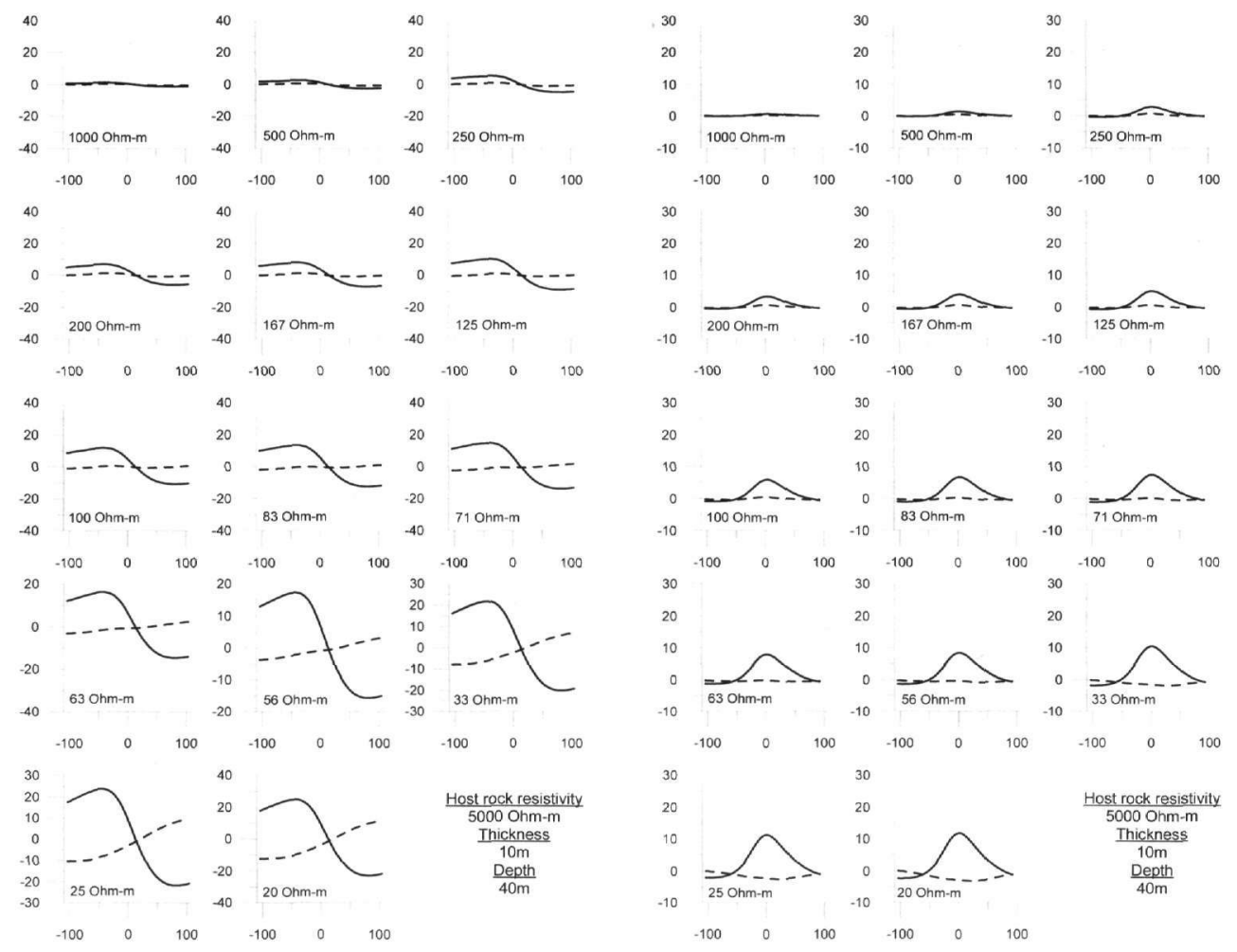

Figure 5 - Raw and filtered data. Target has been moved to the depth of $40 \mathrm{~m}$

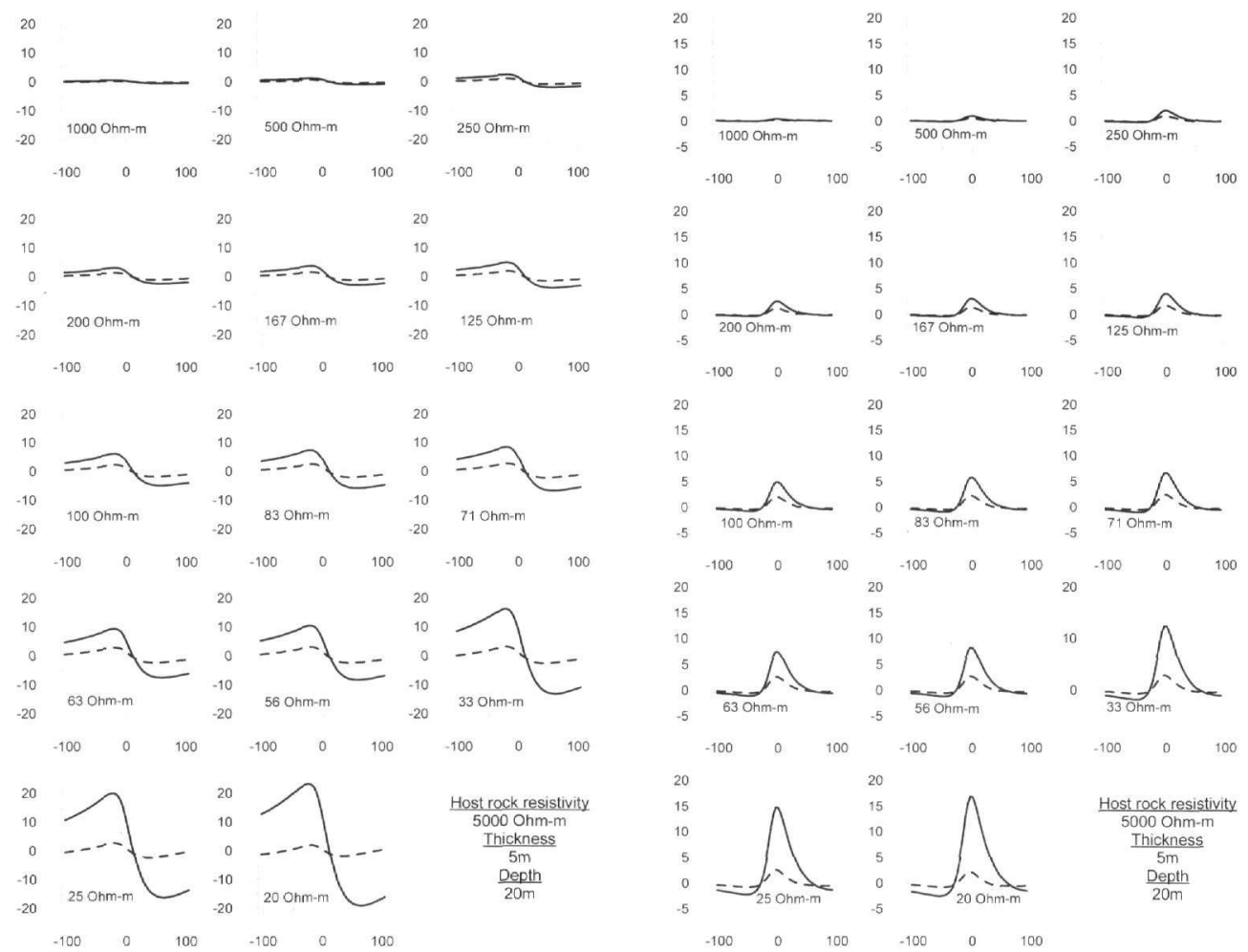

Figure 6 - Raw and filtered data. Target has changed width to $5 \mathrm{~m}$ 


\subsection{Examples from field data}

Two examples of field data are represented. The first one is Lefkochori case (Northern Greece) where the well constructed after the VLF survey suggestion pumped $60 \mathrm{~m}^{3} / \mathrm{h}$ of water and so, it can be considered like a successful one. Geological formation that has been drilled is amphivolites.
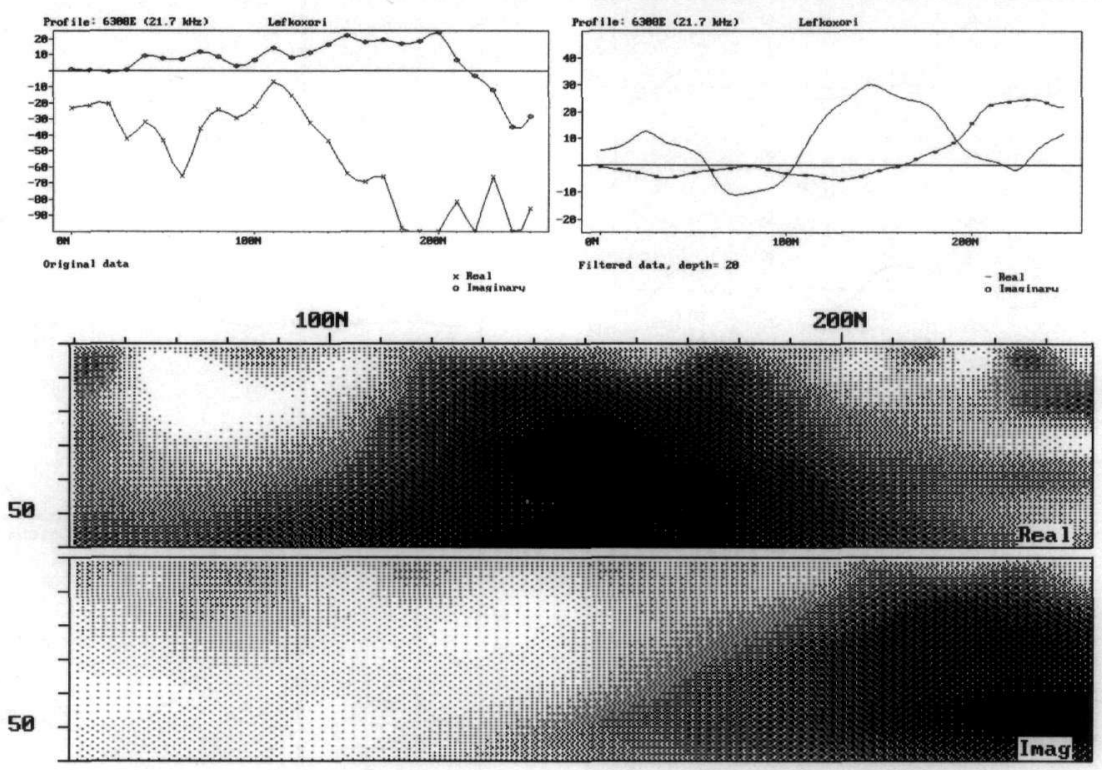

Figure 7 - Raw data (on the top), Fraser filtered data (in the middle) and Karous-Hjelt filtered data (at the bottom)

The expected depth of the fault was approximately 45 meters. We can see that real value is very high (close to 30 in filtered data) and imaginary part is slightly rising up having values close to 0 .

Second case refers to an area investigated in Mavrorachi (Northern Greece). The formation drilled in the present case is granite.
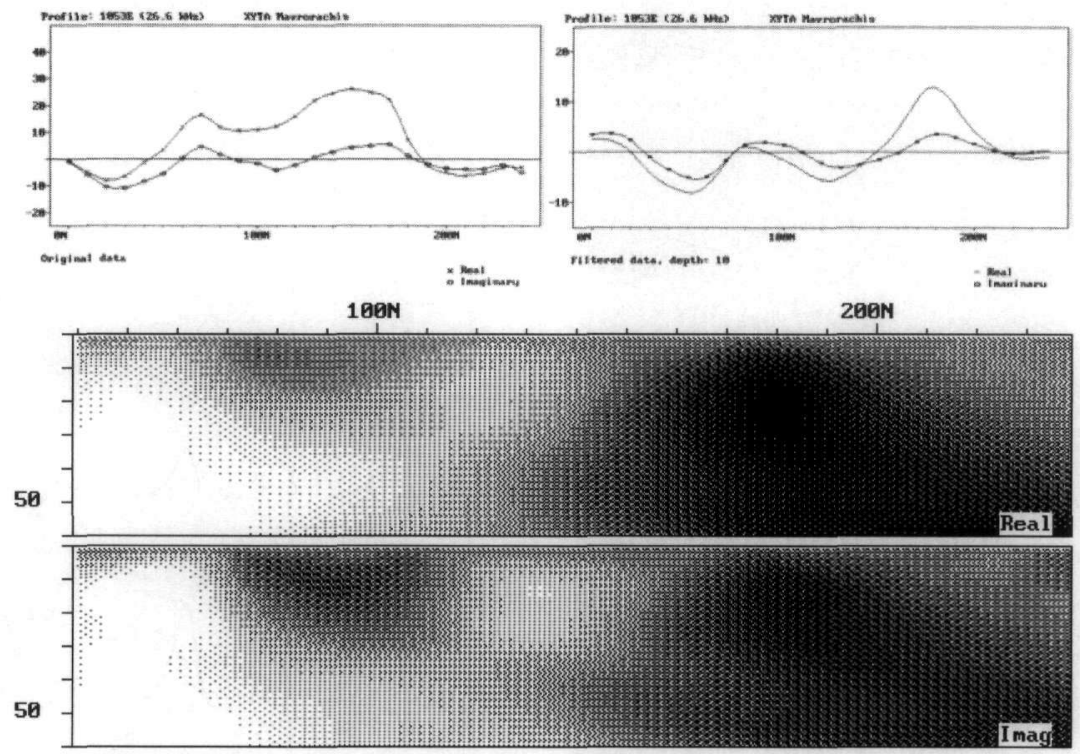

Figure 8 - Raw data (on the top), Fraser filtered data (in the middle) and Karous-Hjelt filtered data (at the bottom) 
In that case we see that even real part is less than in Lefkochori area, imaginary part is forming a positive peak in the centre of the anomaly. That could be an indication of the low resistivity of the conductor as it is proved by the drilling. In the case, no water has been found from the well and it is considered to be a failure. The conductive body that has been detected by the VLF survey refers to talus granite where water exists but the hydraulic properties do not allow the pump of the desired quantity of water. Since the surveyor has to make a decision based on the conductivity of the fault zone, it is very difficult in a case like the present one to discriminate the exploitable underground water from capillary water.

\section{Conclusions}

In the present paper several synthetic cases of different resistivity contrasts between host rock and conductor are examined. The criteria of the examination have been adjusted to hydrogeological survey (porosity, fluid conductivity, type of geological formation).

Examination of forward models show that the criteria that someone must take into account in order to make the right decision - that means drill or not in the first place- are very flexible. In several cases, especially if the conductor is too thin (less than 5 meters) it is very difficult.

It is proposed for a VLF method user to follow several steps for the interpretation of the data and the decision making.

First, estimate the approximate depth of the conductor. That in general is achieved by dividing the distance between maximum and minimum value of the raw real component that is characterized like the detected anomaly.

Then, someone can calculate the desired resistivity values of the conductor in correspondence with the type of the host rock (the bedrock of the area, Table 3).

Then the pattern of the forwarded data can be calculated and be compared with the field data. Since the presence of a conductor is revealed in the first place by the positive anomaly on the real component, special attention must be given to the behaviour of the imaginary component. From the pattern of the lateral one, the conclusion as concern the resistivity of the fault zone can be extracted.

Thus, the decision making may be more accurate and avoid failures like the one presented in the present paper.

\section{References}

Archie, G., 1942. AIME Trans. 146, 54

Benson, A., Payne, K., and Stubben, M., 1997. Mapping groundwater contamination using ds resistivity and VLF geophysical methods - a case study, Geophysics, 62(1), 80-86.

Drahor, M., and Berge, M., 2006. Geophysical investigations of the Seferihisar geothermal area, Western Anatolia, Turkey, Geothermics, 35, 302-320.

Fraser, D.C., 1969. Contouring of VLF-Em data, Geophysics, 34(6), 958-967.

Gharibi, M., and Pedersen, L., 1999. Transformation of VLF data into apparent resistivities and phases, Geophysics, 64(5), 1393-1402.

Hautot, S., Tarits, P., Perrier, F., Tarits, C., and Trique, M., Groundwater electromagnetic imaging in complex geological and topographical regions: A case study of a tectonic boundary in the French Alps, Geophysics, 67(4), 1048-1060.

Hutchinson, P., and Barta, L., 2002. VLF surveying to delineate longwall mine-induced fractures, The Leading Edge, 493. 
Kaikkonen, P., and Sharma, S.P., 1998. 2-D non linear inversion of VLF and VLF-R data using simulated annealing, Journal of Applied Geophysics, 39, 155-176.

Karous, M., and Hjelt, S.E., 1983. Linear filtering of VLF dip-angle measurements, Geophys. Prosp., 31, 782-794.

Keller, E.A., 1996. Environmental Geology $7^{\text {th }}$ edn (Englewood Cliffs, N. J: Prentice-Hall).

McNeill, J.D., and Labson, V.F., 1990. Geological mapping using VLF radio fields. In M. Nabighian (ed.), Electromagnetic Methods in Applied Geophysics, Volume 2, Part B: Tulsa, Oklahoma, Society of Exploration Geophysicists, 521-640pp.

Monteiro Santos, F., Almeida, E., Gomes, M., and Pina, A., 2006. Hydrogeological investigation in Santiago island (Cabo Verde) using magnetotellurics and VLF methods, Journal of African Earth Sciences, 421-430.

Monteiro Santos, F., Mateus, A., Figueiras, J., and Goncalves, M., 2006. Mapping groundwater contamination around a landfill facility using the VLF-EM method - A case study, Journal of Appllied Geophysics 60, 115-125.

Nissen, J., 1986. Versatile programs for geoelectromagnetic interpretation, Doctoral Thesis, Lulea Tekniska Universitet.

Parasnis, D.S, 1995. Principles of Applied Geophysics, Chapman et Hall Ed., Fifth Edition, 429pp.

Sampaio, E., and Dias, C., 2001. Electromagnetic profiling interpretation across vertical faults and dikes, Geophysical Prospecting, 49, 107-119.

Saydam, A., 1981. Very low-frequency electromagnetic interpretation using tilt angle and ellipticity measurements, Geophysics, 46(11), 1594-1605.

Sharma, S.P., and Baranwal, V.C., 2005. Delineation of groundwater-bearing fracture zones in a hard rock area integrating very low frequency electromagnetic and resistivity data, Journal of Applied Geophysics, 57, 155-166.

Zlotnicki, J., Vargemezis, G., Mille, A., Bruere, F., and Hammouya, G., 2006. State of the hydrothermal activity of Soufriere of Guadeloupe volcano inferred by VLF surveys, Journal of Applied Geophysics, 58, 265-279. 